\title{
Regression Analyses for Evaluating the Influence of Bacillus cereus on Alfalfa Yield Under Variable Disease Intensity
}

\author{
Elizabeth R. Kazmar, Robert M. Goodman, Craig R. Grau, David W. Johnson, \\ Erik V. Nordheim, Daniel J. Undersander, and Jo Handelsman
}

\begin{abstract}
First, second, third, and seventh authors: Department of Plant Pathology, University of Wisconsin, Madison 53706; fourth author (current address): Cal/West Seeds, Route 1, Box 70, West Salem, WI 54669; fifth author: Departments of Statistics and Forest Ecology and Management, University of Wisconsin, Madison; and sixth author: Department of Agronomy, University of Wisconsin, Madison. Accepted for publication 7 March 2000.
\end{abstract}

\begin{abstract}
Kazmar, E. R., Goodman, R. M., Grau, C. R., Johnson, D. W., Nordheim, E. V., Undersander, D. J., and Handelsman, J. 2000. Regression analyses for evaluating the influence of Bacillus cereus on alfalfa yield under variable disease intensity. Phytopathology 90:657-665.

We developed and tested regression methods to exploit the variability in disease inherent in field experiments, and applied the methods to evaluate strains of Bacillus cereus for biocontrol efficacy. Four B. cereus strains were tested for their effect on alfalfa (Medicago sativa) performance in 16 field trials planted during 1993 to 1996 at multiple sites in Wisconsin. To evaluate performance of the strains, we used the ratio of (metalaxyl response)/(untreated control response) as a measure of disease intensity within the experiments. The ratio of (Bacillus response)/(untreated control response) was then regressed as a function of disease intensity. The slope of the resulting line provides a statistical test to compare performance of the Bacillus strain with that of the

with seed treated with $B$. cereus strain AS4-12 exceeded yield from the untreated control plots $(P=0.002)$ and was similar to yield of plots planted with metalaxyl-treated seed $(P=0.14)$. Yield gain associated with AS4-12 and metalaxyl seed treatment averaged $6.1 \pm 2.8 \%$ ( \pm standard error) and $3.0 \pm 2.8 \%$, respectively. In contrast to the regression approach, means analysis by analysis of variance did not detect differences among treatments. Three other B. cereus strains either did not increase alfalfa yield or increased yield less than did AS4-12. Metalaxyl and three of the Bacillus strains increased seedling emergence, but the improved stands were not predictive of increased forage yield. In six additional studies conducted for one season in 1997, AS4-12 enhanced yield of two cultivars at diverse locations in Wisconsin, but there was an apparent cultivar-location interaction. A strong correlation between response to AS4-12 and metalaxyl treatment suggests that these treatments controlled similar pathogens, most likely the oomycete pathogens Phytophthora medicaginis and Pythium spp.
\end{abstract} untreated seed $\left(\mathrm{H}_{\mathrm{o}}\right.$ : slope $\left.=0\right)$ and metalaxyl controls $\left(\mathrm{H}_{\mathrm{o}}\right.$ : slope $\left.=1\right)$. Under conditions in which disease occurred, forage yield of plots planted

A major challenge in the development of biocontrol agents is accommodating the variable performance often encountered under field conditions (28). Performance can vary from field to field and year to year, and variability among the replicates within individual field tests can be considerable. In several studies, treatment with biocontrol agents was associated with substantial numerical increases in yield, yet differences were not statistically significant in the face of high unexplained variability (e.g., 34\% increase [6], 24\% increase [26], and 14\% increase [3]). Identification of the biotic and abiotic sources of this variable performance is crucial to improving approaches for selecting, evaluating, and deploying biocontrol agents.

Boland (2) proposed that variation in environmental conditions within experiments results in graduated levels of disease intensity and biocontrol efficacy. He found inclusion of an environmental index based on disease incidence useful in elucidating treatment effects in the presence of high variability. Boland's concept is supported by the observation that biocontrol agents effective in controlling disease can appear ineffective in the absence of disease or when challenged with very high pathogen inoculum (5), implying an interaction between disease intensity and treatment efficacy. Assessment of disease intensity in an experiment, and systematic inclusion of this information in data analysis, may provide insight into biocontrol agent performance.

Corresponding author: J. Handelsman; E-mail address: joh@plantpath.wisc.edu

Publication no. P-2000-0424-01R

(C) 2000 The American Phytopathological Society
Additional keywords: inoculants, plant growth-promoting rhizobacteria.
Alfalfa (Medicago sativa L.) is susceptible to a wide range of pathogens, many with overlapping disease symptoms. The soilborne pathogen complex causing root and damping-off diseases of alfalfa includes Rhizoctonia solani Kühn, Fusarium spp., Pythium spp., Phytophthora medicaginis Drechs. (= Phytophthora megasperma Drechs. f. sp. medicaginis T. Kuan \& D. C. Erwin) (12), and Aphanomyces euteiches Drechs. (21). Yield losses to these pathogens can be substantial $(7,9,10,13,29)$. Host resistance and fungicide seed treatments have increased chances of successful stand establishment and contributed to increased yield under conditions conducive to disease $(13,16,29)$. However, there is still potential for further yield gains through protection from these pathogens. For this reason, we have investigated microbial biocontrol agents as an alternative or supplemental method of control.

Bacillus cereus has proven to have beneficial effects on crop health including enhancement of soybean yield and nodulation $(8$, 18), suppression of damping-off of tomato (22), and suppression of cucumber fruit rot (23). Extensive laboratory data demonstrate a powerful suppression of damping-off disease of alfalfa by diverse strains of $B$. cereus $(11,19,25)$, but only preliminary field data are available (11) because the variability within alfalfa field experiments has stymied such evaluations. In this article, we present data from multiyear field trials to which we applied statistical methods in a new manner to test the hypothesis that seed treatment with $B$. cereus increases emergence and yield of alfalfa under field conditions conducive to diseases caused by oomycete pathogens. 


\section{MATERIALS AND METHODS}

Field sites and data collection. Field experiments were conducted at six locations in Wisconsin (Table 1). Experiments were designed as randomized complete blocks with 5 (1993, 1994, 1995, and 1996) or 10 (1997) replicates. Plot size, alfalfa cultivar, and seeding density differed from year to year (Table 1). Plots were planted by hand at all locations in 1993 and 1994 and at Arlington and Hancock in 1995. The 1995, 1996, and 1997 Marshfield trials were planted with a cone seeder built at the Marshfield Agricultural Research Station of the University of Wisconsin. The remaining 1996 and 1997 trials were planted mechanically with a Wintersteiger 2700 Tool Carrier plot seeder (Wintersteiger, Salt Lake City, UT). Several experiments were irrigated to promote disease (Table 1).

Stand was determined 14 to 21 days after planting by counting the number of emerged seedlings in 1 or $2 \mathrm{~m}$ of row. Yield was measured in the 1993, 1994, and 1995 experiments and in the 1996 West Madison trial by clipping 1-m subsections of row at $10 \%$ bloom and weighing the fresh foliage. In the other trials, entire plots were harvested mechanically with an Almaco Forage Harvester (Allen Machine Co., Nevada, IA). For most trials, yield measurements were made twice in the seeding year and twice in the second season. Only seeding-year yield data were collected for the 1997 trials. The second harvest of the 1997 Lancaster trial was not collected due to weed overgrowth. Herbicides were used in many of the trials for weed control (Table 1) and all trials were hand-weeded as well. Potato leafhoppers (Empoasca fabae Harris) were controlled as needed with applications of permethrin $(0.16 \mathrm{lb}$. a.i. per acre; Zeneca Inc., Wilmington, DE).

Biological materials and seed treatments. Four $B$. cereus strains and five alfalfa cultivars were used in experiments (Tables 2 and 3). In 1993 and 1994, B. cereus cultures were grown in 50\% tryptic soy broth for 4 days at $28^{\circ} \mathrm{C}$ and sporulated cultures applied to seed at the rate of $1 \mathrm{ml}$ of broth per $19 \mathrm{~g}$ of seed. Seed was stirred with the culture and dried in a laminar flow hood with occasional stirring. In 1995, 1996, and 1997, bacterial strains were applied to alfalfa seed by the commercial seed coating company Gustafson (McKinney, TX). Sporulated bacterial slurries were applied to seed in a Hege 11 seed dresser (Hege Equipment, Inc., Colwich, KS). The average bacterial density across years was $5 \times$ $10^{4} \mathrm{CFU}$ per seed. The Apron $25 \mathrm{~W}$ formulation of metalaxyl $(2 \mathrm{oz}$ a.i./hundredweight; Gustafson) was applied in the same manner.

Growth chamber experiments conducted in our laboratory have demonstrated differences in response to B. cereus strain UW85 among eight alfalfa germ plasm groups (data not shown). Therefore, each cultivar tested in a field trial was considered a separate experiment. The following alfalfa cultivars were used in one or more experiments: Iroquois (Cornell University AES, Ithaca, NY), Magnum III (Dairyland Seed Co., West Bend, WI), Multiplier (Mycogen Seeds, Eagan, MN), Rushmore (Novartis Seeds, Inc., Golden Valley, MN), and Webfoot MPR (Great Lakes Hybrids, Ovid, MI).

Data analysis. The 22 field trials fall into two groups: 16 trials established during 1993 through 1996 in which yield was measured during two seasons, and 6 trials planted in 1997 in which yield was measured during the seeding year only. For the 16 experiments begun in 1993 through 1996, harvests collected over two seasons in an experiment were summed for total yield. Emergence and yield ratios in these experiments were calculated using the mean of five replicate observations for each treatment within an experiment. For each bacterial strain, each experiment results in a single data point. In contrast, emergence and yield ratios were calculated for each of 10 replicates in the six trials conducted in 1997 to allow comparison of replicates within trials. Thus, there is a single analysis per bacterial strain for the combined 1993 to 1996 data and six analyses for the 1997 data, one for each combination of three locations and two cultivars.

We calculated a measure of disease intensity by dividing the metalaxyl treatment mean by that of the untreated control within each experiment (1993 to 1996) or within each block (1997). We also divided the treatment mean for each of the four bacterial strains by the mean of the untreated control and regressed these ratios as a

TABLE 1. Description of field sites and experimental details

\begin{tabular}{|c|c|c|c|c|c|c|c|c|c|c|c|}
\hline $\operatorname{Exp}^{t}$ & Year & Site $^{\mathrm{u}}$ & Soil type $^{\mathrm{v}}$ & Alfalfa cultivar & Date $^{w}$ & Plot size & Row spacing & Rate $^{\mathrm{x}}$ & Irrigation $^{y}$ & No. of harvests & Herbicides $^{\mathrm{z}}$ \\
\hline 1 & 1993 & Arl & Plano SL & Iroquois & $5 / 19$ & 2 rows $\times 1 \mathrm{~m}$ & $1 \mathrm{~m}$ & 150 & $\cdots$ & 4 & $\mathrm{E}$ \\
\hline 2 & 1993 & Han & Plainfield sand & Iroquois & $5 / 26$ & 2 rows $\times 1 \mathrm{~m}$ & $1 \mathrm{~m}$ & 150 & $\ldots$ & 4 & $\mathrm{E}$ \\
\hline 3 & 1993 & Mar & Loyal SL & Iroquois & $6 / 29$ & 2 rows $\times 1 \mathrm{~m}$ & $1 \mathrm{~m}$ & 150 & $\ldots$ & 3 & $\mathrm{E}$ \\
\hline 4 & 1993 & WM & Plano SL & Iroquois & $5 / 21$ & 2 rows $\times 1 \mathrm{~m}$ & $1 \mathrm{~m}$ & 150 & $\ldots$ & 4 & E, P \\
\hline 5 & 1994 & Arl & Plano SL & Iroquois & $5 / 17$ & 2 rows $\times 1 \mathrm{~m}$ & $1 \mathrm{~m}$ & 150 & $\ldots$ & 4 & $\mathrm{E}$ \\
\hline 6 & 1994 & Han & Plainfield sand & Iroquois & $8 / 17$ & 2 rows $\times 1 \mathrm{~m}$ & $1 \mathrm{~m}$ & 150 & $\ldots$ & 2 & $\mathrm{E}$ \\
\hline 7 & 1994 & Mar & Loyal SL & Iroquois & $5 / 12$ & 2 rows $\times 1 \mathrm{~m}$ & $1 \mathrm{~m}$ & 150 & $\ldots$ & 4 & $\mathrm{E}$ \\
\hline 8 & 1995 & Arl & Plano SL & MagnumIII & $5 / 26$ & 2 rows $\times 1 \mathrm{~m}$ & $1 \mathrm{~m}$ & 150 & $\ldots$ & 3 & PP \\
\hline 9 & 1995 & Han & Plainfield sand & MagnumIII & $5 / 22$ & 2 rows $\times 1 \mathrm{~m}$ & $1 \mathrm{~m}$ & 150 & $\ldots$ & 4 & $\mathrm{E}$ \\
\hline 10 & 1995 & Mar & Loyal SL & MagnumIII & $5 / 25$ & 2 rows $\times 1 \mathrm{~m}$ & $1 \mathrm{~m}$ & 150 & $\ldots$ & 4 & $\mathrm{E}$ \\
\hline 11 & 1996 & Mar & Marshfield SL & Webfoot MPR & $7 / 3$ & 2 rows $\times 3 \mathrm{~m}$ & $0.3 \mathrm{~m}$ & 100 & $1,2,3$ & 3 & $\mathrm{E}, \mathrm{R}, \mathrm{V}$ \\
\hline 12 & 1996 & Mar & Marshfield SL & Rushmore & $7 / 3$ & 2 rows $\times 3 \mathrm{~m}$ & $0.3 \mathrm{~m}$ & 100 & $1,2,3$ & 3 & $\mathrm{E}, \mathrm{R}, \mathrm{V}$ \\
\hline 13 & 1996 & Mar & Marshfield SL & Multiplier & $7 / 3$ & 2 rows $\times 3 \mathrm{~m}$ & $0.3 \mathrm{~m}$ & 100 & $1,2,3$ & 3 & $\mathrm{E}, \mathrm{R}, \mathrm{V}$ \\
\hline 14 & 1996 & WM & Plano SL & Webfoot MPR & $5 / 13$ & 2 rows $\times 4.3 \mathrm{~m}$ & $0.3 \mathrm{~m}$ & 100 & 1,3 & 3 & $\mathrm{E}, \mathrm{R}$ \\
\hline 15 & 1996 & WM & Plano SL & Rushmore & $5 / 13$ & 2 rows $\times 4.3 \mathrm{~m}$ & $0.3 \mathrm{~m}$ & 100 & 1,3 & 3 & E, R \\
\hline 16 & 1996 & WM & Plano SL & Multiplier & $5 / 13$ & 2 rows $\times 4.3 \mathrm{~m}$ & $0.3 \mathrm{~m}$ & 100 & 1,3 & 3 & $\mathrm{E}, \mathrm{R}$ \\
\hline 17 & 1997 & FDL & Kewaunee RC & Multiplier & $4 / 23$ & 7 rows $\times 4.3 \mathrm{~m}$ & $0.15 \mathrm{~m}$ & 82 & $\ldots$ & 2 & $\mathrm{PP}, \mathrm{R}$ \\
\hline 18 & 1997 & FDL & Kewaunee RC & Rushmore & $4 / 23$ & 7 rows $\times 4.3 \mathrm{~m}$ & $0.15 \mathrm{~m}$ & 82 & $\ldots$ & 2 & $\mathrm{PP}, \mathrm{R}$ \\
\hline 19 & 1997 & Lan & Fayette SL & Multiplier & $4 / 26$ & 7 rows $\times 4.3 \mathrm{~m}$ & $0.15 \mathrm{~m}$ & 82 & $\ldots$ & 1 & $\mathrm{E}$ \\
\hline 20 & 1997 & Lan & Fayette SL & Rushmore & $4 / 26$ & 5 rows $\times 5.5 \mathrm{~m}$ & $0.15 \mathrm{~m}$ & 82 & $\ldots$ & 1 & $\mathrm{E}$ \\
\hline 21 & 1997 & Mar & Marshfield SL & Multiplier & $5 / 20$ & 5 rows $\times 5.5 \mathrm{~m}$ & $0.15 \mathrm{~m}$ & 137 & 1,2 & 2 & E, R \\
\hline 22 & 1997 & Mar & Marshfield SL & Rushmore & $5 / 20$ & 5 rows $\times 5.5 \mathrm{~m}$ & $0.15 \mathrm{~m}$ & 137 & 1,2 & 2 & E, R \\
\hline
\end{tabular}

${ }^{\mathrm{t}}$ Experiment number.

" Arl = Arlington, FDL $=$ Fond du Lac region, Han = Hancock, Lan = Lancaster, Mar = Marshfield, and WM = West Madison. All sites are in Wisconsin and, with the exception of FDL, all are located at Wisconsin Agricultural Experiment Stations.

${ }^{\vee} \mathrm{SL}=$ silt loam, and $\mathrm{RC}=$ red clay.

${ }^{w}$ Planting date, day/month.

${ }^{x}$ Seeding rate, seeds per meter.

y Plots were irrigated to $100 \%$ field capacity for three consecutive days, at the following times: $1=$ the second or third day after planting, $2=4$ weeks after planting, and $3=$ following the first harvest in the second season.

${ }^{\mathrm{z}} \mathrm{E}=$ Eptam (preplant incorporated), $\mathrm{P}=$ Poast (postemergence application), $\mathrm{PP}=$ Poast Plus (postemergence application), $\mathrm{R}=\mathrm{Pursuit}$ (postemergence application), and $\mathrm{V}=$ Velpar (postemergence application). Herbicides were applied at recommended rates. 
function of our measure of disease intensity. The slope of the resulting line describes the performance of the bacterial treatment in a manner that allows comparison with the metalaxyl and untreated controls. In particular, the slope allows us to assess whether a treatment is capable of increasing yield under increasing disease intensity. If the bacterial treatment is not different from the untreated control in this capacity, then the slope of the line will approach 0. If the bacterial treatment is equivalent to metalaxyl in this capacity, then the slope will be 1 . As an additional analytical approach, analysis of variance (ANOVA) and means separation tests according to Fisher's protected least significant difference (24) were conducted on the ratios of treatment means to untreated control means. Regression analyses and two-way ANOVA were conducted in Minitab (version 8; Minitab Inc., State College, PA).

A comparative regression analysis was conducted on the yield data from the 1997 Rushmore-Lancaster trial. First, we conducted a standard ANOVA using block $(n=10)$ and treatment $(n=3)$ as factors to explain the yield. Second, we designed a comparative regression analysis with disease intensity again defined as the ratio of (metalaxyl response)/(control response) as an independent variable. We modified the disease intensity variable so the regression intercept measured yield at mean disease intensity. This was accomplished by subtracting the mean disease intensity from each individual disease intensity value. In this analysis, we regressed raw yield against modified disease intensity and allowed different slopes and intercepts for the three treatments: untreated control, metalaxyl, and strain AS4-12. This can be viewed as an analysis of covariance in which the effect of the covariate (disease intensity) may be different for each treatment. Note that this regression analysis is distinct from that in the previous paragraph. There, (treatment yield)/(control yield) is the $Y$ variable; here, raw yield is the $Y$ variable. For the 1993 to 1996 data set, it was necessary to use (treatment yield)/(control yield) as the $Y$ variable because the different years, field locations, and number of harvests resulted in a wide range of yield potentials. Using this ratio allowed us to normalize the data to remove variability due to the varying conditions. For results from a single trial (e.g., the 1997 trials), such normalization was not required and the "raw" yield was a suitable response variable. However, in both cases, we used (metalaxyl yield)/(control yield) as the predictor variable representing disease intensity.

\section{RESULTS}

1993 to 1996 experiments. Strain AS4-12 enhanced alfalfa emergence and yield more than the other B. cereus strains (Fig. 1; Table 4 ). Slopes obtained from the regression of AS4-12/untreated seed as a function of metalaxyl/untreated seed revealed that emergence

TABLE 2. Source of Bacillus cereus strains used in this study

\begin{tabular}{|c|c|c|c|}
\hline Strain & Location & Source & Reference \\
\hline AS4-12 & Arlington, WI & Soil & 25 \\
\hline HP20-2 & Hancock, WI & Alfalfa root & This study \\
\hline MS1-9 & Marshfield, WI & Soil & 25 \\
\hline UW85 & Arlington, WI & Alfalfa root & 11 \\
\hline
\end{tabular}

TABLE 3. Alfalfa cultivars used in this study

\begin{tabular}{lccc}
\hline & \multicolumn{3}{c}{ Reaction $^{\mathrm{z}}$} \\
\cline { 2 - 4 } Cultivar & P. medicaginis & Race 1 & Race 2 \\
\hline Iroquois & $\mathrm{S}$ & $\mathrm{S}$ & $\mathrm{S}$ \\
Magnum III & $\mathrm{R}$ & $\mathrm{LR}$ & $\mathrm{S}$ \\
Multiplier & $\mathrm{HR}$ & $\mathrm{S}$ & $\mathrm{S}$ \\
Rushmore & $\mathrm{HR}$ & $\mathrm{HR}$ & $\mathrm{S}$ \\
Webfoot MPR & $\mathrm{HR}$ & $\mathrm{R}$ & $\mathrm{S}$ \\
\hline
\end{tabular}

${ }^{\mathrm{z}}$ Host reaction to Phytophthora medicaginis and Aphanomyces euteiches (race 1 and race 2). Percent resistant plants within cultivar population; $\mathrm{S}=$ susceptible (0 to $5 \%), \mathrm{LR}=$ low resistance (6 to $14 \%)$, MR = moderately resistant (15 to $30 \%), \mathrm{R}=$ resistant ( 31 to $50 \%$ ), and $\mathrm{HR}=$ highly resistant $(>50 \%)$.
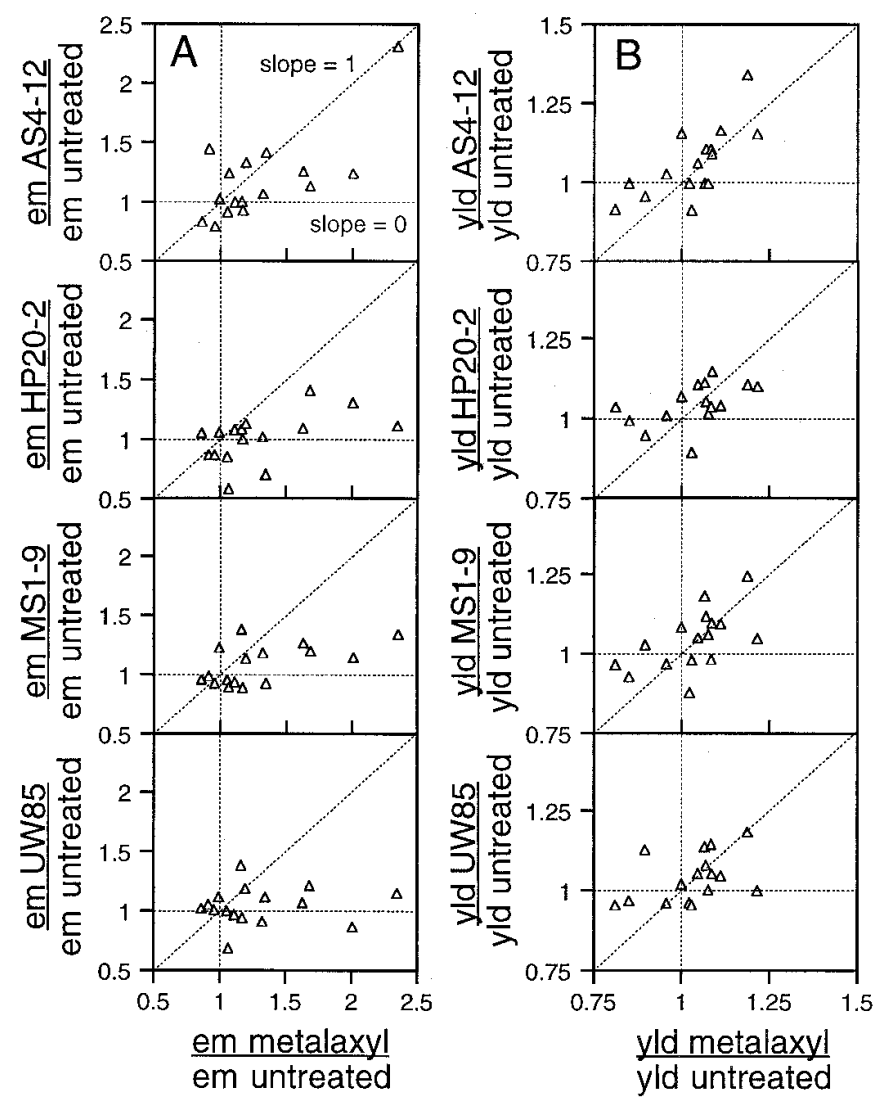

Fig. 1. A, Emergence (em) and B, yield (yld) of alfalfa seed treated with one of four Bacillus cereus strains in field tests planted in 1993, 1994, 1995, and 1996. Response is presented relative to the untreated control and plotted as a function of (metalaxyl response)/(untreated response) as a measure of disease intensity. Each point represents the mean result of one field trial with three to five replicates. Reference lines of slope $=0$ and slope $=1$ are provided in all graphs.

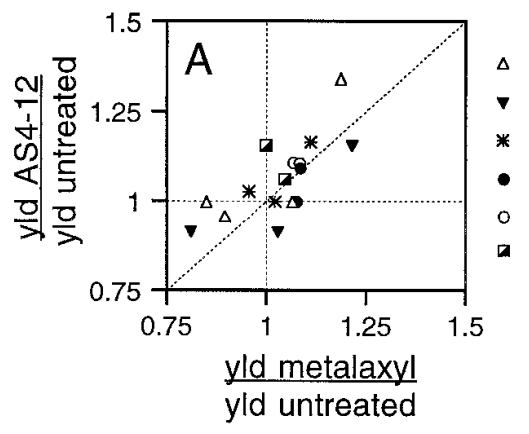

1993, Iroquois

1994, Iroquois

1995, Magnum III

1996, Webfoot MPR

1996, Rushmore

1996, Multiplier

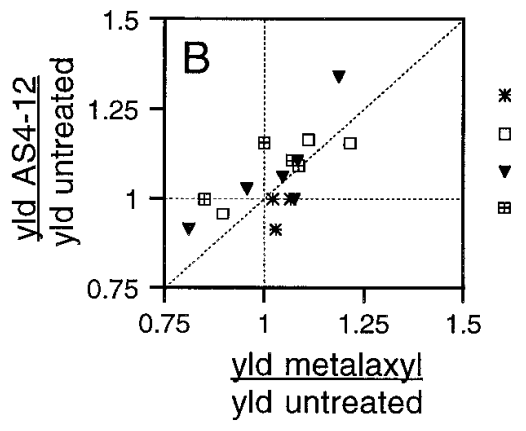

Arlington
Hancock
Marshfield
West Madison

Fig. 2. Yield of alfalfa seed treated with Bacillus cereus strain AS4-12, organized by $\mathbf{A}$, year and cultivar tested or $\mathbf{B}$, field test site. Response is presented relative to the untreated control and plotted as a function of (metalaxyl response)/(untreated response) as a measure of disease intensity. Each point represents the results of one field experiment planted in 1993, 1994, 1995, or 1996. The data are the same as in the AS4-12 portion of Figure 1, but points are identified by important experimental factors. 
of seed treated with AS4-12 was intermediate to and significantly different from both untreated seed $(P=0.002)$ and metalaxyl $(P=$ 0.033 ) (Table 4). ANOVA and means separation analysis of the responses relative to untreated seed demonstrated differences among treatments in emergence, but not in yield (Table 4). The slope corresponding to AS4-12 yield was 0.704, closer to 1 than was the slope of any other treatment. Slope comparisons revealed that alfalfa yield from AS4-12-treated seed was significantly different from untreated seed $(P=0.002)$, but not from metalaxyl $(P=0.140)$. Our power to detect significant statistical difference between "true" slopes of 0.704 and 1 at $\alpha=0.05$ was relatively weak (power $=$ 0.41). However, the lack of statistical significance between the two values, in combination with the numerically greater yield in- crease with AS4-12 over metalaxyl, suggest that AS4-12 is close in efficacy to metalaxyl. This analysis of slope ignores the question of intercept. For virtually all of our data, the fitted lines through the data (Figs. 1, 2, and 3) had $Y$ values close to 1 when disease intensity equaled 1. Metalaxyl and AS4-12 both appear to depress yield when disease intensity is low (Fig. 1B). The decreased yields under low disease intensity contribute to the significant slope. Changes in yield with the AS4-12 seed treatment were distributed across years and across locations (Fig. 2).

The regression approach used for analysis of the 1993 to 1996 data set does not permit statistical comparison of the mean yields, nor does it allow one to determine if the overall change in yield with treatment was positive or negative. Therefore, if statistically
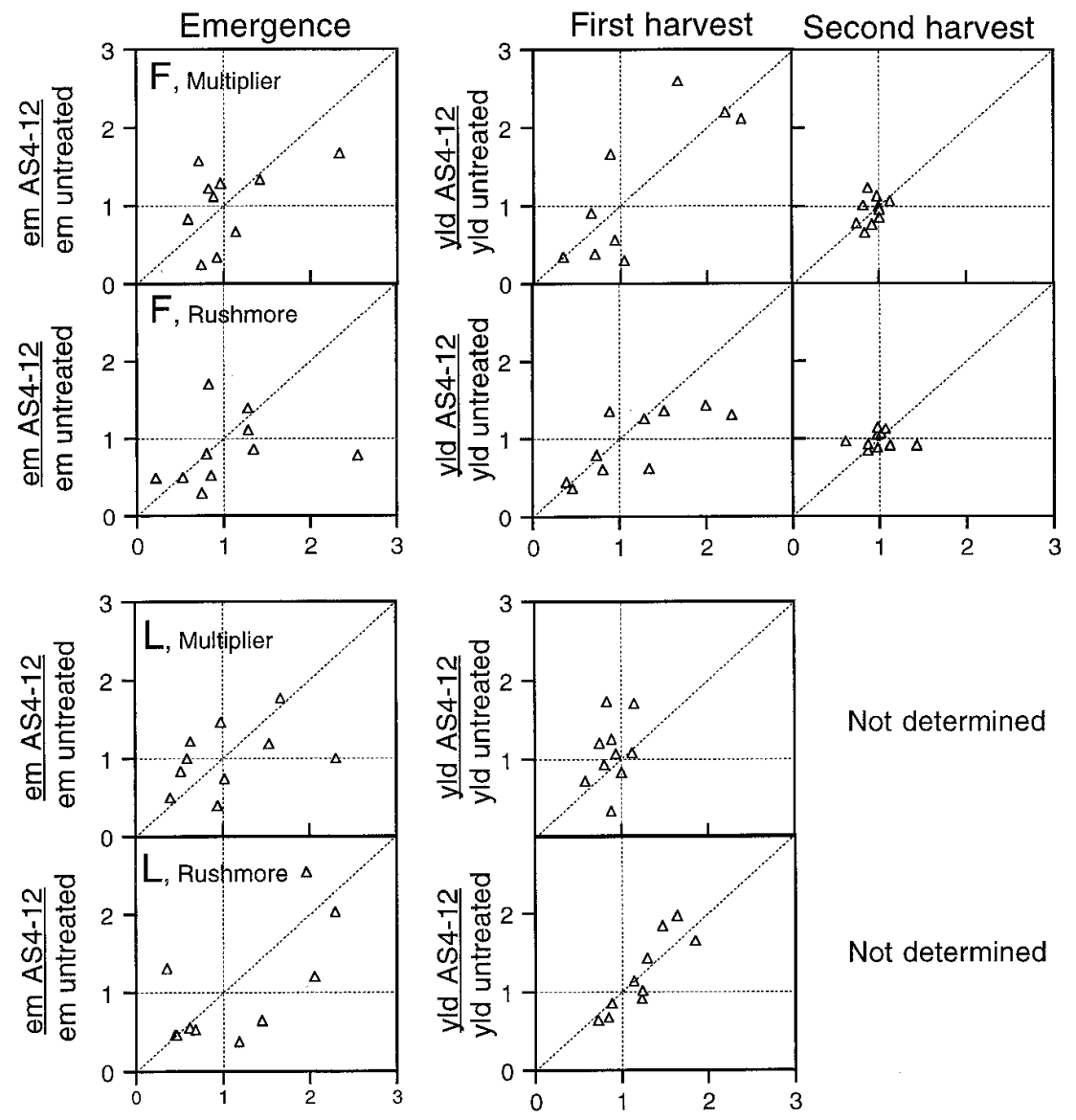

Not determined
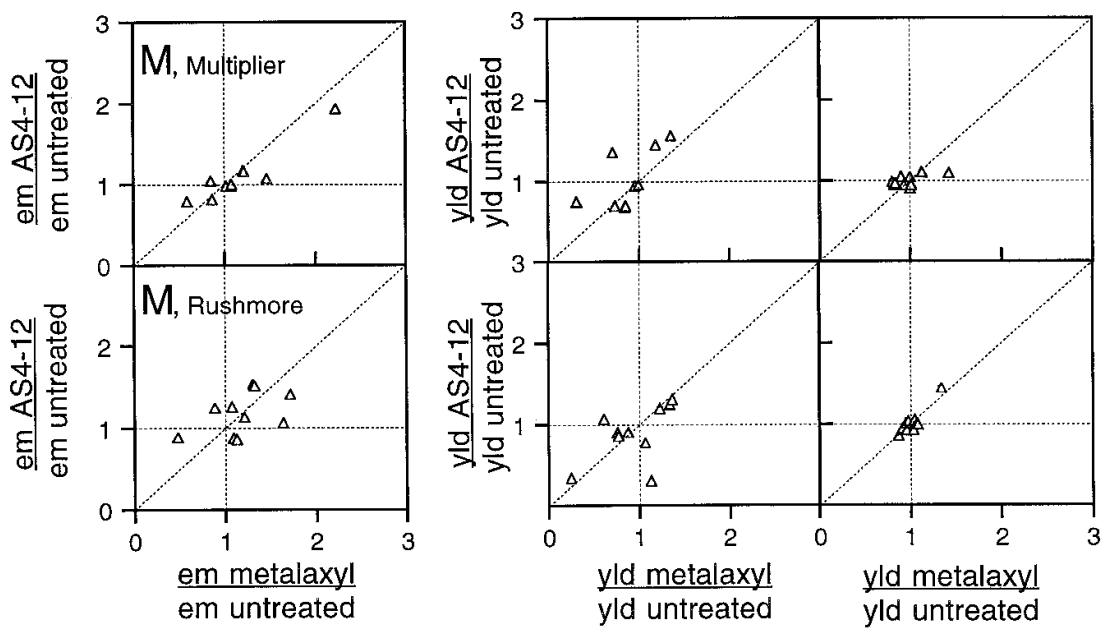

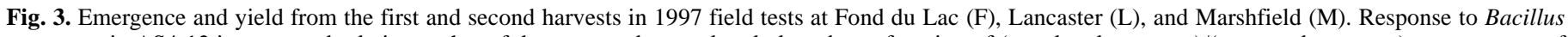

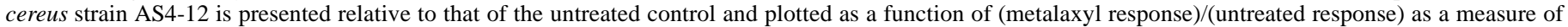
disease intensity. Each point represents a single replicate within the experiment. Reference lines of slope $=0$ and slope $=1$ are provided in all graphs. 
significant differences in slope are first demonstrated among treatments, it is essential to then present the mean yields without statistical comparison in order to summarize the overall benefit associated with the treatments in the trials. Plots planted with AS4-12-treated seed yielded $6.1 \pm 2.8 \%$ ( \pm standard error) more forage than did plots planted with untreated seed. The majority of the yield increase with AS4-12 treatment occurred in the first (+2\%) and second $(+3 \%)$ harvests of the second year. Yield gain with metalaxyl treatment averaged $3.1 \pm 2.8 \%$. These yield increases were not significant under ANOVA.

The 1993 Marshfield trial contributed the highest emergence and yield responses with AS4-12 in this data set. Conditions in this experiment were quite wet and conducive to disease development caused by Phytophthora medicaginis, Pythium spp., and Aphanomyces euteiches. The high disease intensity inferred in this trial makes it both a valuable experiment and an influential point in the analysis, because it shows that AS4-12 appears to have the greatest effect under conditions most conducive to disease. Removal of this influential point results in a reduction in slopes to 0.238 for emergence and 0.524 for yield, values closer to those observed with the other bacterial strains.

The three other B. cereus strains had less effect on alfalfa performance than did AS4-12. There were significant increases in emergence associated with the strains HP20-2 $(P=0.041)$ and
MS1-9 $(P=0.022)$. MS1-9 was associated with a significant effect on yield $(P=0.018)$, and there was very weak evidence of an effect of UW85 on yield $(P=0.105)$.

1997 experiments. We conducted field trials in 1997 with several important changes in design. We increased the number of replicates from 5 to 10 to aid in exploring differences among blocks within trials. Two cultivars were tested for exploration of a cultivar effect on biological control, and we reduced diversity of the treatments to AS4-12, metalaxyl, and no treatment of seed.

The field plot replicates exhibited a dramatic range of responses in the 1997 trials, suggesting that each field contained a mosaic of microenvironments in which effect of seed treatment varied (Fig. 3 ; Table 5). Yield in the first harvest ranged from 0.25 to 2.5 times that of the untreated control in response to AS4-12 or metalaxyl treatment. In all trials, there were several blocks in which yields of AS4-12- and metalaxyl-treated seed were poorer than yield of the untreated control, suggesting that both seed treatments had a negative effect in some areas of the experimental fields. Yield differences with treatment were less pronounced in the second harvest than in the first harvest.

Both of the alfalfa cultivars tested in 1997 showed a significant yield response to AS4-12 treatment at one or more, but not all, sites. The responses (again, the ratio of treatment to control) showed the following interaction between site and cultivar. Yield of AS4-12-

TABLE 4. Effect of Bacillus cereus seed treatments on emergence and yield of alfalfa in 16 field trials conducted during 1993 through 1996

\begin{tabular}{|c|c|c|c|c|c|c|c|c|c|c|}
\hline \multirow{3}{*}{$\begin{array}{l}\text { Observation and } \\
\text { interpretation }^{\mathrm{y}}\end{array}$} & \multicolumn{10}{|c|}{ Chemical or biological treatment } \\
\hline & \multicolumn{5}{|c|}{ Emergence } & \multicolumn{5}{|c|}{ Yield } \\
\hline & Apron & AS4-12 & HP20-2 & MS1-9 & UW85 & Apron & AS4-12 & HP20-2 & MS1-9 & UW85 \\
\hline Slope & $\ldots$ & 0.614 & 0.255 & 0.229 & 0.046 & $\ldots$ & 0.704 & 0.312 & 0.499 & 0.290 \\
\hline$P$ value $\left(\mathrm{H}_{\mathrm{o}}:\right.$ slope $\left.=0\right)$ & $\cdots$ & $0.002^{*}$ & $0.041^{*}$ & $0.022 *$ & 0.660 & $\ldots$ & $0.002 *$ & 0.204 & $0.018^{*}$ & 0.105 \\
\hline $\begin{array}{c}\mathrm{H}_{\mathrm{o}}: \text { bacterium }=\text { untreated } \\
P \text { value }\left(\mathrm{H}_{\mathrm{o}}: \text { slope }=1\right) \\
\mathrm{H}_{\mathrm{o}}: \text { bacterium }=\text { Apron }\end{array}$ & $\ldots$ & $0.033 *$ & $<0.001 *$ & $<0.001 *$ & $<0.001^{*}$ & $\ldots$ & 0.142 & $0.011 *$ & $0.017 *$ & $<0.001 *$ \\
\hline$R^{2}(\%)$ & $\ldots$ & 51 & 26 & 32 & 1 & $\ldots$ & 50 & 11 & 34 & 18 \\
\hline Mean response ${ }^{z}$ & $1.30 \mathrm{a} \mathrm{B}$ & $1.18 \mathrm{ab} B$ & $1.01 \mathrm{c} \mathrm{A}$ & $1.08 \mathrm{bc} \mathrm{A}$ & $1.04 \mathrm{bc} \mathrm{A}$ & $1.03 \mathrm{a} \mathrm{A}$ & $1.06 \mathrm{a} A$ & $1.03 \mathrm{a} \mathrm{A}$ & $1.04 \mathrm{a} A$ & $1.04 \mathrm{a} \mathrm{A}$ \\
\hline
\end{tabular}

y Regression analysis of bacterial treatment/untreated seed as a function of Apron/untreated seed. $*=P$ values $<0.05$.

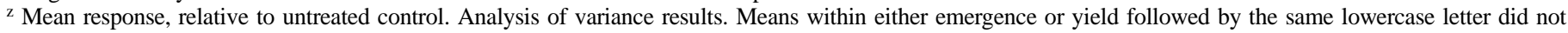
differ significantly $(\alpha=0.05)$. Uppercase letters: $A=$ means not significantly different and $B=$ means significantly different from the untreated control $(\alpha=0.05)$.

TABLE 5. Mean alfalfa emergence and yield as influenced by Bacillus cereus strain AS4-12 or metalaxyl seed treatment in the 1997 trials ${ }^{\mathrm{V}}$

\begin{tabular}{|c|c|c|c|c|c|c|}
\hline \multirow{2}{*}{$\begin{array}{l}\text { Site, } \\
\text { seed treatment }{ }^{\mathrm{w}}\end{array}$} & \multicolumn{2}{|c|}{ Proportion emerged } & \multicolumn{2}{|c|}{ First harvest (tons/acre) } & \multicolumn{2}{|c|}{ Second harvest (tons/acre) } \\
\hline & cv. Multiplier & cv. Rushmore & cv. Multiplier & cv. Rushmore & cv. Multiplier & cv. Rushmore \\
\hline \multicolumn{7}{|l|}{ FDL } \\
\hline Untreated & 0.55 & 0.57 & 0.512 & 0.866 & 1.202 & 1.113 \\
\hline Metalaxyl & 0.50 & 0.54 & 0.512 & 0.872 & 1.123 & 1.085 \\
\hline AS4-12 & 0.45 & 0.43 & 0.469 & 0.735 & 1.130 & 1.080 \\
\hline Slope ${ }^{\mathrm{x}}$ & 0.46 & 0.17 & 1.02 & 0.503 & 0.556 & 0.011 \\
\hline$P$ value $(\text { slope }=0)^{\mathrm{y}}$ & 0.17 & 0.49 & $0.009 *$ & $0.014 *$ & 0.32 & 0.95 \\
\hline$P$ value $(\text { slope }=1)^{\mathrm{z}}$ & 0.11 & $0.008 *$ & 0.94 & $0.014 *$ & 0.42 & $0.006^{*}$ \\
\hline \multicolumn{7}{|l|}{ Lan } \\
\hline Untreated & 0.33 & 0.41 & 0.732 & 0.846 & ND & ND \\
\hline Metalaxyl & 0.30 & 0.38 & 0.646 & 0.965 & ND & ND \\
\hline AS4-12 & 0.31 & 0.32 & 0.771 & 0.926 & ND & ND \\
\hline Slope & 0.28 & 0.69 & 0.797 & 1.20 & ND & ND \\
\hline$P$ value $($ slope $=0)$ & 0.25 & $0.029 *$ & 0.37 & $<0.001 *$ & ND & ND \\
\hline$P$ value $($ slope $=1)$ & $0.013^{*}$ & 0.28 & 0.81 & 0.40 & ND & ND \\
\hline \multicolumn{7}{|l|}{ Mar } \\
\hline Untreated & 0.44 & 0.47 & 0.476 & 0.765 & 0.845 & 0.822 \\
\hline Metalaxyl & 0.48 & 0.53 & 0.498 & 0.730 & 0.819 & 0.832 \\
\hline AS4-12 & 0.47 & 0.53 & 0.477 & 0.699 & 0.837 & 0.828 \\
\hline Slope & 0.68 & 0.34 & 0.753 & 0.533 & 0.229 & 0.543 \\
\hline$P$ value $($ slope $=0)$ & $<0.001 *$ & 0.18 & $0.064 *$ & 0.10 & $0.063^{*}$ & $0.073 *$ \\
\hline$P$ value $($ slope $=1)$ & $0.007 *$ & $0.020 *$ & 0.49 & 0.15 & $<0.001 *$ & 0.12 \\
\hline
\end{tabular}

v Alfalfa cultivars used: Multiplier and Rushmore; ND = not determined.

${ }^{\mathrm{w}}$ Sites: FDL = Fond du Lac, Lan = Lancaster, and Mar = Marshfield.

${ }^{x}$ Regression of AS4-12/untreated seed as a function of metalaxyl/untreated seed.

y $\mathrm{H}_{\mathrm{o}}$ : AS4-12 = untreated, $*=P$ values $<0.05$.

${ }^{\mathrm{z}} \mathrm{H}_{\mathrm{o}}$ : AS4-12 = metalaxyl, ${ }^{*}=P$ values $<0.05$. 
treated Multiplier was significantly different from untreated seed at Fond du $\operatorname{Lac}(P=0.009)$, but not at Lancaster $(P=0.370)$, as quantified by the comparison of slopes. In contrast, yield response of AS4-12-treated Rushmore was intermediate between untreated seed $(P=0.014)$ and metalaxyl $(P=0.014)$ at Fond du Lac, but was strongly different from untreated seed at Lancaster $(P<0.001)$. AS4-12 treatment did not have a marked effect on yield of either cultivar at Marshfield. Thus, multiple cultivars were responsive to AS4-12 treatment, but there appeared to be a substantial treatment by cultivar by site interaction.

Assessment of variability within one trial. One objective of our study was to quantify the impact of using disease intensity to describe the variability among plots. Quantification was achieved through comparison of the ANOVA and the comparative regression procedure of the 1997 Rushmore-Lancaster data set. We chose this data set because it provides a clear illustration of how plot-to-plot variability in disease intensity influences treatment detection by ANOVA. The ANOVA results led to no significant effect for treatment, a high mean square for error, and, consequently, an $R^{2}$ value equal to $35.3 \%$ (Table 6). The high mean square error is due, at least in part, to a block by treatment interaction (data not shown).

Therefore, we employed the comparative regression model for analysis of our data. The initial fitted model allows different slopes and different intercepts for the three treatments (Table 7). Analysis consisted of removing, in a sequential manner, all nonsignificant terms. The final model suggested that metalaxyl and AS4-12 performed comparably (Table 8); neither slope was significantly different from 0 or from each other. In addition, the lines for the two treatments had the same intercept. The control treatment was different. The intercept differed significantly from that of metalaxyl and AS4-12. The intercepts obtained from the comparative regression provide an estimate of yield at mean disease intensity (Table 8). Note that these estimated values are comparable to the actual mean yield values $(0.844$ for untreated seed, 0.967 for metalaxyl, and 0.927 for AS4-12). In addition, the slope of untreated seed $(-0.667)$ differed significantly from the slopes of AS4-12 and metalaxyl (0). The predicted values from the resultant model demonstrate this pattern (Fig. 4). The mean square for error is much smaller in the comparative regression analysis (Table 9) versus the ANOVA (Table 6), and the $R^{2}$ value is $58.1 \%$ compared with $35.3 \%$. Thus,

TABLE 6. Analysis of the first yield of cv. Rushmore in the 1997 Lancaster trial by analysis of variance ${ }^{z}$

\begin{tabular}{lccccc}
\hline Source & $\begin{array}{c}\text { Degrees of } \\
\text { freedom }\end{array}$ & $\begin{array}{c}\text { Sequential } \\
\text { sum of squares (SS) }\end{array}$ & $\begin{array}{c}\text { Adjusted } \\
\text { mean square }\end{array}$ & $F$ & $P$ value \\
\hline Block & 9 & 0.275 & 0.031 & 0.86 & 0.56 \\
Seed treatment & 2 & 0.074 & 0.039 & 1.04 & 0.35 \\
Error & 18 & 0.638 & 0.035 & $\ldots$ & $\ldots$ \\
Total & 29 & 0.987 & $\ldots$ & $\ldots$ & $\ldots$ \\
\hline
\end{tabular}

${ }^{\mathrm{z}} R^{2}=35.3 \%=100[1-(\mathrm{SSError} / \mathrm{SST}$ Total)]. Conclusion: there were no significant differences among treatments.

TABLE 7. Model for the comparative regression analysis of the first yield of cv. Rushmore in the 1997 Lancaster trialy $^{\mathrm{y}}$

\begin{tabular}{llc}
\hline Term & \multicolumn{1}{c}{ Identity } & $P$ value \\
\hline Constant & Intercept for AS4-12 & $<0.001^{\mathrm{z}}$ \\
$\mathrm{d}$ & Slope for AS4-12 & $\mathrm{NS}^{\mathrm{z}}$ \\
I1 & Difference in intercept between control and AS4-12 & 0.047 \\
I2 & Difference in intercept between metalaxyl and AS4-12 & $\mathrm{NS}$ \\
dI1 & Difference in slope between control and AS4-12 & $<0.001$ \\
dI2 & Difference in slope between metalaxyl and AS4-12 & $\mathrm{NS}$ \\
\hline
\end{tabular}

y This analysis describes yield at mean disease intensity. The initial model included all the terms listed. The significance of each term in the final model is indicated. The final fitted model was yield $=0.945-0.0997$ I1 $0.666 \mathrm{dI} 1$.

${ }^{\mathrm{z}}$ The $P$ value results from a test of whether the intercept or slope differs from 0 . NS $=$ not significant. accounting for disease intensity removed a considerable amount of the variability in the system and allowed us to detect treatment effects in the data.

The standard ANOVA model can only allow comparison of the means of the treatments averaged over blocks. Given that the disease intensity was different in the different blocks and that the responses of the three treatments to disease intensity were not the same, the comparative regression analysis is necessary to describe the data. We examined a subset of our individual field trials and found that some did not follow the treatment patterns described in Table 5 and Figure 4. In some cases, for example, yield of the untreated control did not change with increasing disease intensity, whereas yield of metalaxyl- and AS4-12-treated seed increased. Therefore, one cannot conclude that the behavior of B. cereus AS412 and metalaxyl as described in Tables 6 to 9 and Figure 4 is representative of their performance under all conditions. Nonetheless, in many trials, our measure of disease intensity proved valuable in accounting for the variability among plots.

\section{DISCUSSION}

We found that B. cereus strain AS4-12 increased the yield of multiple alfalfa cultivars at diverse sites within Wisconsin under conditions in which disease limited yield. Regression of AS4-12 yield on an estimate of disease intensity within the trials allowed detection of treatment effects. We propose that the spatial heterogeneity in disease intensity documented in our alfalfa trials may be a common source of the high variation observed in field tests with biocontrol agents (28). The regression analysis presented here offers an approach to extract information from natural variation by investigating biocontrol efficacy under the range of disease environments present in a single field. Failure to consider such natural variation and the resulting interactions with efficacy of the biocontrol agent is likely to contribute to inflated error rates and underestimates of the significance of treatment effects. The existence of this variability can result in violations of underlying assumptions in analysis with the ANOVA model. Our findings are in agreement with Boland (2), who drew similar conclusions in field studies of biological control of white mold of bean (Sclerotinia sclerotiorum (Lib.) de Bary). Heterogeneity in disease intensity is not the sole source of variability in biocontrol trials, and there are other sources to consider as well $(17,20,28)$.

We describe two regression analyses in this study, both using an estimate of disease intensity as the independent $X$ variable. Selection of the appropriate regression depends on the data set collected. If one is interested in combining data from diverse experiments, then the dependent $Y$ variable data should be normalized to an internal control and the main regression approach presented here is appropriate. For example, normalization is essential when combining yield data across locations with different yield potential. In contrast, the raw treatment response can be used when examining data from single trials; the comparative regression analysis is appropriate in such cases and is favored because it provides both intercept and slope comparisons among the treatments. Our approach offers an alternative to the use of microplots (1) and other methods in which inoculum densities are quantified or artificially amended

TABLE 8. Modeled values of slope and intercept at mean disease intensity obtained from the comparative regression analysis of the first yield of alfalfa cv. Rushmore in the 1997 Lancaster trial

\begin{tabular}{lcc}
\hline & \multicolumn{2}{c}{ Intercept $^{\mathrm{z}}$} \\
\cline { 2 - 3 } Treatment & Estimated yield (tons/acre) & Slope \\
\hline Untreated & $0.845 \mathrm{~b}$ & $-0.667 \mathrm{~b}$ \\
Metalaxyl & $0.945 \mathrm{a}$ & $0 \mathrm{a}$ \\
AS4-12 & $0.945 \mathrm{a}$ & $0 \mathrm{a}$ \\
\hline
\end{tabular}

$\mathrm{z}$ Values within a column followed by the same letter did not significantly different at $\alpha=0.05$. 
before the trial is established. Our approach is more amenable to the large-scale testing necessary for realistic yield assessments and is useful for diseases that are strongly influenced by environmental conditions as well as inoculum density.

To use the regression analyses described here, several key features in experimental design must be considered. First, a method to estimate disease severity within the individual plots of an experiment must be included. Direct assessment of disease severity is not practical for some diseases, such as root rots, and other estimates of disease intensity must be found. Although we used a synthetic fungicide, comparison of susceptible and resistant germ plasm can also provide an indicator of disease. Inoculum density might provide another useful $X$ variable. We prefer the disease intensity variable for our system, because root rots are sensitive to environmental conditions such as soil moisture and because of the difficulty of quantifying inoculum for all the pathogens involved in the alfalfa root rot complex. Second, treatments must be compared within regions of relative disease homogeneity; a blocked design is appropriate. Limiting the number of experimental treatments will keep the blocks small and avoid introducing unexplained variation. One could pair each treatment plot with its own control plots, but this approach would require dedicating a large fraction of the test area to the controls and would be quite inefficient. Analytical precision will be strengthened by choosing fields in which a broad range of disease intensities is likely to be encountered. Thus, disease intensity should be homogeneous within blocks, but heterogeneous among blocks. Third, experimental designs should be suitable for analysis by either ANOVA or regression. Some field sites may lack the broad range of disease intensities necessary to elucidate formation of a line with disease intensity as the $X$ variable. In such cases, the ANOVA model is preferable to regression. Fourth, the regression approach benefits from higher levels of replication than from the four or five replicates that are typical of field experiments designed to be analyzed by ANOVA. In our comparative regression analysis, each replicate contributed one data point in the evaluation of any given treatment. Power considerations based on our results suggest that 10 is a reasonable number of replicates for ranges of disease intensity comparable to those we encountered.

Interpretation of results should accommodate the following issues. A significant positive slope demonstrates the treatment's capacity to improve yield as disease increases. In general, the slope itself cannot be used to evaluate the mean yield. If the majority of the experimental points fall in the upper right quadrant of the graph, a significant yield gain is implicit. However, it is possible for a treatment to have a slope significantly greater than 0 , yet still have a mean yield lower than untreated seed. This could occur if the majority of points on figures similar to those presented here fall in the lower left or right quadrants. Even in such a case, the slope demonstrates the treatment's capacity to increase yield with increased disease, despite an overall yield loss. Therefore, it is essential that data plots or treatment means be provided to facilitate a full interpretation of the results. We note that, in some circumstances, it might be advantageous to transform the dependent and independent variables to improve linearity. This was not necessary for the data presented here.

Several additional features should be considered in application of our comparative regression analysis. First, we strongly advise

TABLE 9. Analysis of variance for the comparative regression analysis of the first yield of alfalfa cv. Rushmore in the 1997 Lancaster trial $^{\mathrm{Z}}$

\begin{tabular}{lccccc}
\hline Source & $\begin{array}{c}\text { Degrees of } \\
\text { freedom }\end{array}$ & $\begin{array}{c}\text { Sequential } \\
\text { sum of squares (SS) }\end{array}$ & $\begin{array}{c}\text { Adjusted } \\
\text { mean square }\end{array}$ & $F$ & $P$ value \\
\hline Regression & 2 & 0.573 & 0.287 & 18.7 & $<0.001$ \\
Error & 27 & 0.414 & 0.015 & $\ldots$ & $\ldots$ \\
Total & 29 & 0.987 & $\ldots$ & $\ldots$ & $\ldots$ \\
\hline $\mathrm{z}$ & & & & &
\end{tabular}

${ }^{\mathrm{z}} R^{2}=58.1 \%$ that the initial model allow for all possible slopes and intercepts, not just those identified as significant in our model. Second, the comparative regression analysis allows conclusions to be reached analogous to those obtained from a means separation test. Our test of the hypothesis of equal intercepts can be interpreted as a test for the hypothesis of equal yields at mean disease intensity. Third, this test can be modified to test the hypothesis of equal yields at any disease intensity of interest. This can be accomplished by subtracting the disease intensity value of interest from each disease intensity observation, rerunning the regression analysis, and examining the new intercepts. For example, one could examine treatment responses in the absence of disease by comparing intercepts at a disease intensity of 1 in each trial. By evaluating the significance of the individual intercepts (Table 7, terms I1 and I2), pairs of individual treatments can be compared.

Our evidence suggests that seed application of $B$. cereus strain AS4-12 has practical potential. AS4-12 treatment is associated with yield increases of alfalfa and is similar in effect on yield to the existing commercial seed treatment metalaxyl. The magnitude of the response to AS4-12 varied among the experiments, but was greatest under conditions in which disease occurred, as revealed by performance of the metalaxyl control. In particular, the highly diseased conditions in the 1993 trial at Marshfield contributed substantially to our conclusion of superior performance by AS4-12. The high disease intensity encountered in this trial naturally makes it both a valuable experiment and an influential point in our analysis. The established ability of metalaxyl to suppress Phytophthora spp. and Pythium spp. disease strongly suggests that suppression of these pests is involved in response to AS4-12. Treatment with AS4-
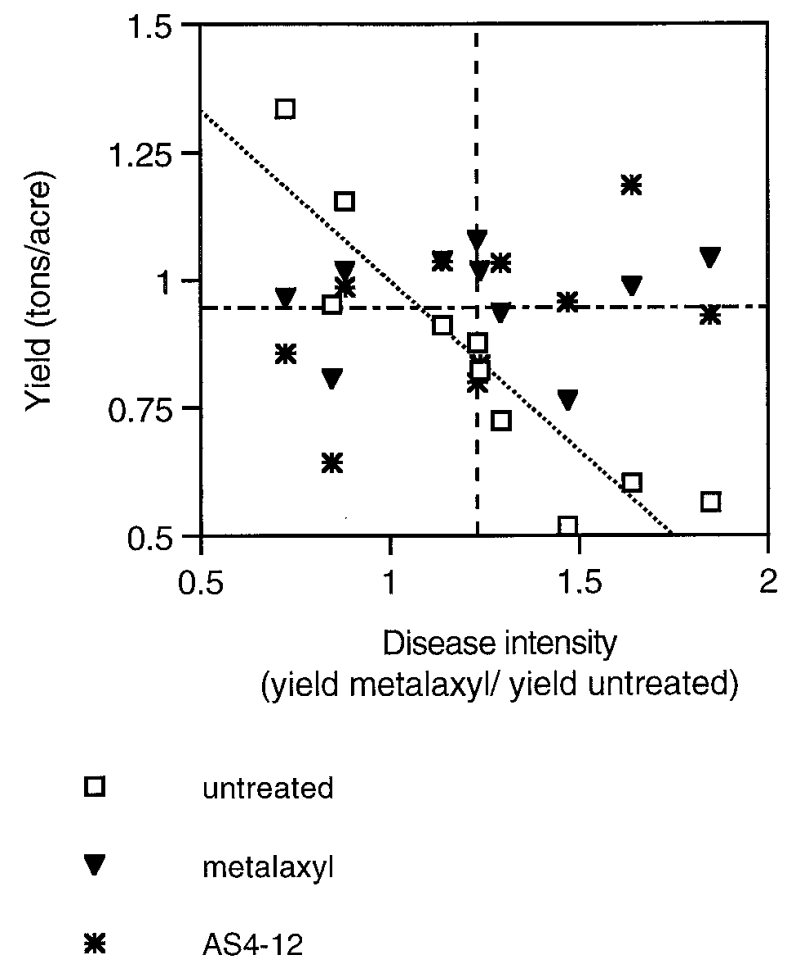

Modeled performance of metalaxyl and of AS4-12

.................. Modeled performance of the untreated control

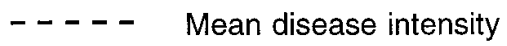

Fig. 4. Performance of AS4-12-treated, metalaxyl-treated, and untreated alfalfa cv. Rushmore seed in the 1997 Lancaster trial. Each point represents yield collected in the first harvest from a single replicate. The lines are derived from comparative regression analysis (Tables 7, 8, and 9). 
12 was associated with a $6.1 \pm 2.8 \%$ increase in yield over 2 years, averaged across 16 field tests conducted from 1993 through 1996. Yield gain with metalaxyl treatment averaged $3.1 \pm 2.8 \%$. These changes in mean yield over untreated seed were not significant when examined by ANOVA. Our data set may be representative of other biocontrol studies in which significant differences are not demonstrated among treatments by ANOVA. We encourage other researchers to apply the regression methods described here before concluding that their treatments are ineffective. AS4-12 was effective under the diverse field conditions encountered in Wisconsin on multiple cultivars, but response is apparently mediated by the interaction of cultivar and location.

There were two unexpected results in these experiments. First was the mediocre performance of UW85 in the field. This strain was originally identified for its ability to suppress alfalfa dampingoff in the lab, where it offers highly effective biological control of Phytophthora medicaginis (11) and Pythium torulosum (D. W. Johnson, L. M. Jacobson, K. P. Smith, E. R. Kazmar, C. R. Grau, J. Handelsman, and R. M. Goodman, unpublished data) on alfalfa. UW85 also promotes consistent yield increases of soybean in fields conducive to diseases caused by Phytophthora sojae and Pythium spp. (18). The second unexpected result was the persistence of benefits from seed treatment with AS4-12 into the second year of the alfalfa stand. Yields in the 1993 to 1996 trials are the sum of harvests collected over 2 years. The second-year harvests contributed a $5 \%$ increase in total yield, a considerable portion of the total $6 \%$ yield gain. These results are consistent with other studies demonstrating that stress during the seeding year can influence alfalfa yield in subsequent seasons (27).

Metalaxyl was more effective than AS4-12 in protecting alfalfa from seedling damping-off, yet yields of alfalfa treated with the two seed coatings were similar, suggesting that improved stand establishment is not predictive of increased yield. Our study highlights the importance of measuring effects on yield and not relying on improved emergence as an indicator of successful biological control. It is unclear whether the emergence increase associated with metalaxyl treatment is simply unrelated to yield of the alfalfa stand or if the more modest emergence gains observed with AS412 treatment are causally linked to increased yield.

Attention to the individual replicates within an experiment can yield useful information about conditions in which biocontrol efficacy is poor and, thereby, identify topics of future research. For example, the source of the slight negative effects associated with both metalaxyl and AS4-12 treatment in the 1993 to 1996 trials and in some regions of the 1997 fields is not obvious. Fungicide treatments protective against one pathogen can lead to increased disease by nontarget pathogens. Studies in alfalfa (10) and cotton (4) revealed a balance between root infection by Pythium spp. and Rhizoctonia spp. and demonstrated that fungicide treatments protective against one pathogen were associated with increased disease by the other. This may have occurred in some blocks of our trials. The observed suppression under low disease intensity contributes to the statistical significance of the slopes. Recognition of conditions under which fungicides or biological agents fail is the first step toward designing approaches to combat the problem.

Research efforts to increase alfalfa productivity have met with only modest success. For example, yield gains through breeding have been small $(14,15)$. Holland and Bingham (15) estimate the rate of alfalfa yield improvement through breeding efforts to be $0.20 \%$ per year for germ plasm released between 1940 and 1985 . The slow rate of gain demonstrates the challenge of working with the complex alfalfa crop and highlights the value of modest increases in yield that can be achieved through improved crop production practices, such as disease control. Thus, the $6 \%$ yield enhancement reported here represents a substantial contribution to alfalfa production. Detection of small gains depends on sensitive statistical methods. Identification of the sources of the high variability chronically associated with biocontrol studies will aid in development and adoption of this promising low-impact technology for alfalfa and other crops.

\section{ACKNOWLEDGMENTS}

This work was supported by grants from the USDA Competitive Grants Program in IPM for the North Central Region (grant no. 92-34103-7170), the Wisconsin Department of Development Applied Research in Technology program (contract no. ART 91-6), the Center for Integrated Agricultural Systems at the University of Wisconsin/Madison, Gustafson Inc., and the University of Wisconsin College of Agricultural and Life Sciences. We thank L. Jacobson for selection of the bacterial strains used in this study and for assistance with field trials; K. Silveira and D. Wiersma for assistance with field trials; the R. Kastening family for providing the 1997 Fond du Lac field site; Gustafson, Inc., for seed treatment applications; K. Smith for discussions of the statistical analysis; P. Vincelli for a thoughtful review of the manuscript; and many student laborers for their hard work with the field trials.

\section{LITERATURE CITED}

1. Barker, K. R., Daughtry, B. I., and Corbet, D. W. 1979. Equipment and techniques for establishing field microplots for the study of soilborne pathogens. J. Nematol. 11:106-107.

2. Boland, G. J. 1997. Stability analysis for evaluating the influence of environment on chemical and biological control of white mold (Sclerotinia sclerotiorum) of bean. Biol. Control 9:7-14.

3. Burr, T. J., Schroth, M. N., and Suslow, T. 1978. Increased potato yields by treatment of seed pieces with specific strains of Pseudomonas fluorescens and $P$. putida. Phytopathology 68:1377-1383.

4. Davis, R. M., Nunez, J. J., and Subbarao, K. V. 1997. Benefits of cotton seed treatments for the control of seedling diseases in relation to inoculum densities of Pythium species and Rhizoctonia solani. Plant Dis. 81: 766-768

5. Deacon, J. W., and Berry, L. A. 1993. Biocontrol of soil-borne plant pathogens: Concepts and their application. Pestic. Sci. 37:417-426.

6. Duffy, B. K., and Weller, D. M. 1995. Use of Gaeumannomyces graminis var. graminis alone and in combination with fluorescent Pseudomonas spp. to suppress take-all of wheat. Plant Dis. 79:907-911.

7. Frosheiser, F. I. 1980. Conquering Phytophthora root rot with resistant alfalfa cultivars. Plant Dis. 64:909-912.

8. Halverson, L. J., and Handelsman, J. 1991. Enhancement of soybean nodulation by Bacillus cereus UW85 in the field and in a growth chamber. Appl. Environ. Microbiol. 57:2767-2770.

9. Hancock, J. G. 1985. Fungal infection of feeder rootlets of alfalfa. Phytopathology 75:1112-1120.

10. Hancock, J. G. 1993. Fungal rootlet colonization and forage yields of alfalfa in fungicide-treated field plots. Plant Dis. 77:601-608.

11. Handelsman, J., Raffel, S., Mester, E. H., Wunderlich, L., and Grau, C. R. 1990. Biological control of damping-off of alfalfa seedlings with $B a$ cillus cereus UW85. Appl. Environ. Microbiol. 56:713-718.

12. Hansen, E. M., and Maxwell, D. P. 1991. Species of the Phytophthora megasperma complex. Mycologia 83:376-381.

13. Havey, M. J., and Grau, C. R. 1985. Decline of established alfalfa in soils naturally infested with Phytophthora megasperma f. sp. medicaginis and level of correlation by seedling assay. Plant Dis. 69:221-224.

14. Hill, Jr., R. R., Shenk, J. S., and Barnes, R. F. 1988. Breeding for yield and quality. Pages 809-825 in: Alfalfa and Alfalfa Improvement, Agronomy Monograph 29. A. A. Hanson, D. K. Barnes, and R. R. Hill, Jr., eds. ASA, CSSA, and SSSA, Madison, WI.

15. Holland, J. B., and Bingham, E. T. 1994. Genetic improvement for yield and fertility of alfalfa cultivars representing different eras of breeding. Crop Sci. 34:953-957.

16. Holub, E. B., and Grau, C. R. 1990. Productivity and survival of alfalfa ramets in soil naturally infested with Aphanomyces euteiches and Phytophthora megasperma. Can. J. Plant Pathol. 12:83-91.

17. Höper, H., and Alabouvette, C. 1996. Importance of physical and chemical soil properties in the suppressiveness of soils to plant diseases. Eur. J. Soil Biol. 32:41-58.

18. Osburn, R. M., Milner, J. L., Oplinger, E. S., Smith, R. S., and Handelsman, J. 1995. Effect of Bacillus cereus UW85 on the yield of soybean at two field sites in Wisconsin. Plant Dis. 79:551-556.

19. Raffel, S. J., Stabb, E. V., Milner, J. L., and Handelsman, J. 1996. Genotypic and phenotypic analysis of zwittermicin A-producing strains of Bacillus cereus. Microbiology 142:3425-3436. 
20. Ristaino, J. B., Lewis, J. A., and Lumsden, R. D. 1994. Influence of isolates of Gliocladium virens and delivery systems on biological control of southern blight on carrot and tomato in the field. Plant Dis. 78:153-156.

21. Schmitthenner, A. F. 1964. Prevalence and virulence of Phytophthora, Aphanomyces, Pythium, Rhizoctonia, and Fusarium isolated from diseased alfalfa seedlings. Phytopathology 54:1012-1018.

22. Smith, K. P., Handelsman, J., and Goodman, R. M. 1999. Genetic basis in plants for interactions with disease-suppressive bacteria. Proc. Natl. Acad. Sci. U.S.A. 96:4786-4790.

23. Smith, K. P., Havey, M. J., and Handelsman, J. 1993. Suppression of cottony leak of cucumber with Bacillus cereus strain UW85. Plant Dis. 77: $139-142$.

24. Snedecor, G. W., and Cochran, W. G. 1980. Statistical Methods, 7th ed. The Iowa State University Press, Ames.
25. Stabb, E. V., Jacobson, L. M., and Handelsman, J. 1994. Zwittermicin Aproducing strains of Bacillus cereus from diverse soils. Appl. Environ. Microbiol. 60:4404-4412.

26. Suslow, T. V., and Schroth, M. N. 1982. Rhizobacteria of sugarbeets: Effects of seed application and root colonization on yield. Phytopathology 72:199-206.

27. Undersander, D. J., Hogg, D. B., and Grau, C. R. 1997. Effect of current year stress on succeeding year alfalfa production. Page 104 in: Agronomy Abstracts, 89th Annu. Meet. ASA, CSSA, and SSSA, Madison, WI.

28. Weller, D. M. 1988. Biological control of soilborne plant pathogens in the rhizosphere with bacteria. Annu. Rev. Phytopathol. 26:379-407.

29. Wiersma, D. W., Grau, C. R., and Undersander, D. J. 1995. Alfalfa cultivar performance with differing levels of resistance to Phytophthora and Aphanomyces root rots. J. Prod. Agric. 8:259-264. 